\title{
El héroe y el traidor: Simón Bolívar y José Domingo Díaz
}

\author{
Alicia Ríos \\ Syracuse University
}

En "Tema del traidor y del héroe" de Jorge Luis Borges, ese estupendo relato que puede leerse de tantas maneras, Ryan, bisnieto del "heroico, del bello, del asesinado Fergus Kilpatrick" (328), mártir de la independencia irlandesa, está escribiendo su biografía y, para ello, revisa documentos relacionados con la muerte de su famoso antepasado. En su investigación descubre que, además de ser el héroe nacional, también "fue un conspirador, un secreto y glorioso capitán de conspiradores", y que "pereció en la víspera de la rebelión victoriosa que había premeditado y soñado" (328). Descubre asimismo que quien contó originalmente su muerte fue "el más antiguo de los compañeros del héroe" (329), Alexander Nolan, quien plagió su relato con referencias textuales de los dramas shakesperianos de Julio César y Macbeth, así como de los Festpiele suizos, todo ello porque "Irlanda idolatraba a Kilpatrick; la más tenue sospecha de su vileza hubiera comprometido la rebelión"; así pues, "Nolan propuso un plan que hizo de la ejecución del traidor el instrumento para la emancipación de la patria" (330). Al final, Ryan decide no contar la "verdad" y repetir una vez más la "limpia" historia de Kilpatrick.

La historiografía y la literatura nos cuentan muchas veces historias que inventan/tergiversan/entrelazan los hechos, siempre justificándose por la necesidad de mantener el orden, la libertad, la imagen del héroe y la patria. Como veremos, algo similar ocurre con dos figuras claves de la independencia venezolana: Simón Bolívar y José Domingo Díaz.

La mayoría de los estudios pertinentes a la época de la independencia en Venezuela han compartido implícita o explícitamente dos ideas fundamentales que me interesa cuestionar: primero, que la clase letrada constituyó un grupo homogéneo donde la raza o el color de la piel no jugó ningún papel y, segundo, que hubo notables diferencias no solo a nivel ideológico sino de expresión entre los dos bandos en pugna, el patriota y el realista.

Sin embargo, al revisar los dos periódicos más importantes durante cuatro de los años de mayor intensidad bélica, 1818-1822 -la Gaceta de Caracas (monárquico) y el Correo del Orinoco (republicano)-, puede constatarse que, aunque cada uno de los bandos defendió implacablemente sus posiciones, por demás encontradas, ambos emplearon recursos similares y recurrieron a estrategias de representación muy semejantes. Por el otro lado, al revelarse contundentemente hace pocos años la condición parda/de color del médico expósito editor del periódico realista, José Domingo Díaz, unida a la descalificación virulenta y recurrente en sus escritos ante la condición mantuana/ criolla de Simón Bolívar, no queda otro camino que incorporar las tensiones étnicas o raciales dentro del propio grupo letrado. Estas tensiones dominaron 
el período no solo entre el campo letrado y el "popular", también dentro de este primer grupo.

En conjunto con su evidente carácter internacional, la guerra de independencia venezolana fue inexorablemente una guerra civil y racial: Ios criollos -quienes representaban de manera sustancial el menor porcentaje de la población ${ }^{1-}$ querían ejercer el poder político que les era prohibido desde España, mientras que los pardos (letrados, profesionales y campesinado libre o no), junto con los esclavos negros, veían la posibilidad de vengarse de los consabidos excesos de los blancos. Esta lucha de clases se acrecentó con la participación de José Tomás Boves (en los años 13 y 14), quien logró movilizar a los llaneros para que lucharan contra los republicanos. A pesar de que en 1815, luego de la llegada del "Pacificador" Pablo Morillo -general al mando del mayor ejército traído a América- se logró unir a todos los grupos y, más tarde, se consolidó el triunfo patriota, la lucha interna continuó; para 1819 "la burguesía terrateniente y comercial reasumió [...] la dirección plena de la guerra, no solo teórica sino prácticamente, reduciendo el aporte popular consistente en la nueva promoción de caudillos que serán los realizadores concretos de la victoria" (Carrera Damas, 45-46). Esto fue progresivamente contribuyendo al triunfo del general José Antonio Páez, quien al final logró unir a los llaneros (pardos, en su mayoría) bajo la bandera patriota, así como a los militares y comerciantes que se oponían a los intereses centralistas del Libertador; no por casualidad, entonces, fue Páez el primer Presidente de Venezuela en su camino como Estado-nación independiente. Bolívar no dejó nunca de ser visto por muchos como el mantuano defensor de los intereses de su clase, y a ello recurrieron una y otra vez sus opositores, sobre todo el médico pardo José Domingo Díaz.

En el imaginario ilustrado y romántico de la época, no solo se peleaba en los campos de batalla, también desde la prensa, pues era la palabra escrita la que en última instancia permitiría la consolidación definitiva. La prensa constituyó uno de los aparatos de captura a los que recurrió cada bando para alcanzar su objetivo: ganar la guerra y, consecuentemente, consolidar su propio Estado; por medio de ella se fueron construyendo los símbolos, representaciones y emblemas sobre los cuales se asentó o desestabilizó cada grupo y, en particular, mediante la prensa se comenzó a "narrar" la nación. Los periódicos posibilitaron la construcción de un sujeto colectivo, el público. Esta punción permitió la inserción de nuevos valores simbólicos en relación con la ciudadanía, la masculinidad, la subalternidad y los bordes en la arena social.

El Libertador Simón Bolívar fue uno de los más notables representantes del mantuanaje. Gracias a una inmensa fortuna familiar pudo disfrutar de las mejores oportunidades: además de contar con la instrucción de dos de los más reconocidos maestros latinoamericanos de todos los tiempos -Andrés

\footnotetext{
1 Los estudios concernientes a la población preindependentista los colocan en $20 \%$. Inés Quintero, una de las historiadoras más acuciosas al estudiar ese período, afirma que para 1789 la Provincia de Venezuela "contaba apenas con 300.000 habitantes, de los cuales, 70.000 eran esclavos, y el resto, al menos las dos terceras partes eran gente libre de casta, zambos, negros y mulatos" $(2006,336)$.
} 
Bello y Simón Rodríguez-, pudo viajar y ponerse en contacto directo con las ideas y acontecimientos más importantes del momento (presenció incluso, en 1804, la coronación de Napoleón en París). Nació en una familia que representaba los más puros privilegios de clase.

En Venezuela a esa oligarquía criolla se le llamó mantuanos. Desde 1571, Felipe II había incorporado una

disposición en la que las mulatas y las negras libres o esclavas no podían llevar oro o seda, mantos ni perlas. Si eran casadas con español, se les permitía usar unos zarcillos [aretes] de oro con perlas, una gargantilla y un ribete de terciopelo en la saya o falda. Les estaba prohibido, so pena de confiscación, el uso de joyas, ropas de seda y mantos de cualquier tipo de tela. Tan solo podían llevar mantellinas o mantillas un poco más abajo de la cintura, pues los mantos estaban reservados a damas de mayor jerarquía (Sosa Cárdenas, 29)².

Pardos, por otro lado, eran llamados todos aquellos de quienes se sospechaba tenían alguna mezcla negra, así fuera en antepasados remotos (Lynch, 192-193); podían ser libres o esclavos, aunque aquellos que gracias a sus artes, educación o trabajo adquirían cierto nivel económico, eran catalogados como "pardos beneméritos" (Sosa Cárdenas, 26-27).

Bajo una estricta jerarquización racial imperaba, como puede advertirse, un riguroso régimen de castas que impregnaba las costumbres, e incluso el vestir, coloniales. La ascendencia negra era duramente penalizada y constituía una barrera con frecuencia inquebrantable dentro de dicha sociedad. No obstante, debido al desarrollo económico que fueron progresivamente alcanzando los llamados pardos beneméritos, la Corona se vio forzada interesadamente en consentir una mayor flexibilidad en esta categorización, siempre y cuando los interesados tuvieran cómo pagar ese ascenso social. En 1795, la Real Cédula de Aranjuez (denominada Gracias al Sacar) abrió un diminuto espacio legal donde podía alcanzarse cierto "blanqueamiento" que, aunque era ferozmente rechazado por la clase mantuana, permitió rasgar algunos espacios por orden directa del rey. Este grupo "apelaba a una pureza, no de sangre, sino de haber mantenido su 'calidad' por generaciones, casándose entre ellos y evitando uniones con los estratos inferiores" (Sosa Cárdenas, 32). Podían aspirar exclusivamente a escalar un escaño social más, el de "blanco del 'estado llano', constituido por blancos pobres, extranjeros europeos y quinterones" (37).

Para los comienzos independentistas, el grupo de los pardos beneméritos estaba compuesto no solo por músicos y artesanos, sino por militares (quienes participaban en batallones especiales) o médicos (los blancos criollos desdeñaban la medicina porque tradicionalmente esta profesión había sido ejercida por curanderos de color sin estudios formales).

2 Cfr. también Mangano-Molero, 50. 
La ascendencia india, sin embargo, no era necesariamente penalizada; sus portadores eran tomados por mestizos, no gente de color/pardos, y luego de la quinta generación (o quinterón) eran considerados de la misma jerarquía social que los españoles o criollos, es decir, eran "gente de calidad" (Sosa Cárdenas, 44). Una de las figuras más relevantes dentro de este grupo fue el conocido jurista Juan Germán Roscio, quien escribió muchos de los documentos fundacionales de la nueva república y quien participó en repetidas ocasiones en la redacción del Correo del Orinoco. Roscio era hijo de una mestiza cuarterona y un padre blanco. En 1798, al prohibírsele el ingreso al Colegio de Abogados, una vez terminados sus estudios, presentó una querella -que duró siete años y finalmente falló a su favor- donde él mismo alegaba participar de una condición superior a la parda. Se apoyó legalmente en las leyes indianas, las que "establecían que los indígenas podían casarse con españolas y los peninsulares con indígenas y criollas. Esto, debido a que se les reconoció desde el principio como súbditos de la Corona bajo la protección directa del Rey" (Sosa Cárdenas, 44).

\section{José Domingo Díaz: expósito y pardo benemérito}

La época de la independencia (1808-1830) ha sido la más estudiada dentro de la historiografía venezolana. La presencia en un mismo periplo de tiempo de cinco figuras tan importantes a nivel continental como lo fueron Francisco de Miranda, Simón Rodríguez, Andrés Bello, José Antonio Sucre y Simón Bolívar, desencadenó desde los meros inicios nacionales innumerables estudios donde repetidamente se han resaltado las condiciones privilegiadas con que contaba la ciudad de Caracas, tanto a nivel económico como cultural, en los momentos previos a las luchas independentistas hispanoamericanas. El Libertador Simón Bolívar, a la cabeza de esta lista, ha permeado la mayoría de estas lecturas incluso hasta nuestros días, construyéndose con él -y gracias a él ${ }^{3}$ - un culto a su figura que pocas veces ha permitido algún espacio a otros personajes e ideas. Todo esto se acrecienta aún más si queremos buscar información acerca del bando de los vencidos (si bien es muy común no conocer "la visión de los vencidos" en cualquier acontecimiento histórico, el vacío de este grupo es aún más marcado en el caso venezolano, sobre todo si se analiza cuantitativamente el porcentaje de publicaciones historiográficas dedicadas al período en comparación a otros países de la región)4; es recién en esta última década que han comenzado a aparecer con alguna fuerza estudios que insisten finalmente en la necesidad de incorporar al bando realista en cualquier análisis de la gesta heroica republicana.

El caso de José Domingo Díaz es emblemático al respecto, pues es una figura de la cual prácticamente no se tiene noticia: por ser enemigo confeso del Libertador lo convirtió, pese a su indudable presencia e importancia en la época, en alguien completamente al margen del posterior discurso historiográfico bolivariano; en los pocos registros de su persona siempre se le calificó como "traidor". Sus muy escasas referencias giraron siempre alrededor de

3 Cfr. Carrera Damas (1973), Castro Leiva y Ríos (2013).

4 Cfr. Straka (2007). 
su trabajo como editor de la Gaceta de Caracas, en su etapa realista, con mínimas menciones a sus Recuerdos sobre la Rebelión de Caracas, libro de memorias que Díaz publicó en Madrid en 1829 y del que solo se han hecho tres ediciones posteriores a la original. La primera no ocurrió hasta 1961, bajo los auspicios de la Academia Nacional de la Historia. Las "Palabras preliminares" y edición, a cargo de Ángel Francisco Brice, se enfocaron en justificar la necesidad de dicho volumen, no sin corregir en todo momento los "exabruptos" de Díaz hacia la causa republicana y, sobre todo, hacia Bolívar. Las otras dos ediciones son recién del 2011 y 2012 (la primera, editada nuevamente por la Academia Nacional de la Historia, tiene un estudio preliminar titulado "Monárquico por convicción. José Domingo Díaz y sus Recuerdos sobre la Rebelión de Caracas", de Inés Quintero, que finalmente presenta adecuadamente a Díaz y, la segunda, publicada por la Fundación Biblioteca Ayacucho, tiene un excelente prólogo de Marianela Tovar Núñez, "En busca del paraíso perdido: la vivencia de José Domingo Díaz de la guerra de independencia en Venezuela").

Toda la información concerniente a su origen es confusa y contradictoria (parece haber nacido en Caracas con el nombre de Joseph Domingo Parbulo, "los primeros días del mes de agosto del año 1772 y fue registrado como expósito en el libro de bautismo de blancos de la iglesia de La Candelaria"5). En lo único que hay consenso es en que fue un niño expósito, es decir, no conoció a sus padres por ser fruto de una unión ilegal, y fue criado por dos hermanos sacerdotes -Domingo y Antonio Díaz Argote-, de quienes tomó su apellido (aunque solo usaba el Díaz); había algunos rumores en su tiempo de que su verdadero padre era uno de ellos. Gracias a ambos, según unos pocos historiadores, pudo completar sus estudios; otros le atribuyen su manutención al famoso curandero mulato Juan José Castro, alias Juancho Castro, quien habría sido su verdadero progenitor con una mujer blanca de la alta sociedad. Ese origen oscuro fue denunciado anónimamente en algunos momentos claves y se utilizó evidentemente para descalificarlo, pues el hijo de un curandero de color no podía de ninguna manera expresarse con "la verdad"6. Su condición de expósito no fue inusual en la Caracas de la época, lo acompañan en ella nada menos que el ya mencionado Simón Rodríguez y José Félix Blanco (quien alcanzó el grado de general en el ejército republicano mientras fungía, al mismo tiempo, como sacerdote al servicio de la Iglesia). En ciertos casos se elegía esta condición de expósito expresamente, de manera de permitirle a los hijos la posibilidad de ejercer los oficios o empleos de los blancos, pues era considerado menos negativo ser expósito que de color (Archila, 203). En el caso de Díaz, Tomás Straka afirma que la condición parda le fue perdonada por tener primacía la de expósito $(2007,34)$.

La escasa historiografía acerca de Díaz insiste en que se involucró con el bando realista y no el republicano al volver de Sevilla, donde se encontraba

\footnotetext{
5 Tovar Núñez, IX.

6 Para desprestigiarlo, el 15 de noviembre de 1813, por ejemplo, estando en manos patriotas, apareció reproducido en la Gaceta de Caracas un texto anónimo, que había circulado previamente en Curazao, donde se le atribuía un padre mulato, el curandero Juan José (Juancho) Castro; se cree que fue escrito por uno de sus más enconados enemigos mantuanos, Vicente Salias.
} 
durante los sucesos del 19 de abril de 1810 (cuando comenzó la insurgencia hispanoamericana desde Caracas), porque la Junta Defensora de los Derechos de Fernando VII no le reconoció el cargo de Director de Hospitales con el que había regresado al país. Sin duda esto puede haber sido un motivo importante en su adhesión a la causa realista, pero no pienso que puede ser la única razón: las tensiones raciales en la Caracas de la época deben también haber influido, sobre todo al revisar el encono con que este se dirigía a la clase mantuana en sus artículos. Su evidente resentimiento ante los criollos no implicó, sin embargo, una posición reivindicativa hacia el resto de la población de color. Como buen pardo benemérito, despreciaba a los grupos inferiores. Al comentar a propósito de una conspiración descubierta a finales de 1811 cuyo objetivo era darle preferencia a las castas por sobre la raza blanca, su comentario en sus Recuerdos sobre la Rebelión de Caracas fue de absoluta indignación: "Inconcebible extravío del espíritu humano y prueba convincente de cuánto es capaz el hombre abandonado a sí mismo" (36).

En realidad, no se conoce ningún escrito donde Díaz se defienda o aclare estas acusaciones acerca de su origen familiar: siempre mantuvo un impugnable silencio al respecto. Incluso en sus Recuerdos... son muy escasas las instancias en donde aporta datos específicos de su biografía, a pesar del tono evidentemente personal de las memorias (donde cuenta sus experiencias al volver de Sevilla y presenciar la ofensiva republicana) y de su insistencia en proveer fechas y recuerdos bastante específicos de la mayoría de los acontecimientos narrados. Aunque algunos no han pensado que haya nada inusual en este silencio, pienso que Díaz nunca escribió nada precisamente por su origen "oscuro", en los dos sentidos del término: racial e ilegal. Para un pardo expósito y benemérito, referirse a su origen iba en contra de los principios sobre los cuales se había configurado este grupo. De haber podido siquiera sugerir un origen claramente blanco, no creo posible que habría dudado en hacerlo (pues nunca se destacó precisamente por su prudencia o humildad al escribir).

Por razones obvias, Díaz fue muy cercano a las autoridades españolas (tanto al capitán general Vasconcelos como a Monteverde y, posteriormente, a Morillo), si a esto le añadimos su condición de pardo benemérito, no es de sorprender el encono desplegado contra él en una ciudad tan estratificada social y racialmente como Caracas.

\section{El Correo del Orinoco y la Gaceta de Caracas}

Desde 1808, cuando comenzaron los pasos definitivos hacia la independencia, hasta 1830, cuando Venezuela comenzó su camino como Estado-nación independiente, se conoce de por lo menos setenta y un periódicos. Así como ha afirmado Pedro Grases, al seguir el itinerario de la prensa periódica puede rastrearse en detalle el desarrollo de la contienda bélica: "Caracas (1808); Cumaná (1811); Angostura (1818); Maracaibo (1821); Guanare y Puerto Cabello (1825); Valencia (1830)" (II 332). Aunque solo dos de estos periódicos lograron la circulación, continuidad e importancia necesarios para marcar una verdadera diferencia dentro de la meseta independentista: la Gaceta de Caracas y el Correo del Orinoco. 
La Gazeta de Caracas $^{7}$ fue el primer periódico publicado en Venezuela; apareció en la ciudad capital bastante puntualmente, si consideramos los tiempos que corrían, desde el 24 de octubre de 1808 hasta el 3 de enero de $1822^{8}$. Estuvo en manos patriotas o realistas dependiendo de las vicisitudes de la guerra9. En los años que nos ocupan, 1818-1822, estuvo dirigida básicamente por José Domingo Díaz ${ }^{10}$ (a quien debemos la famosa imputación al Libertador, entre muchas otras, "la democracia en los labios y la aristocracia en el corazón" (Gaceta, 19 de abril de 1815)). Díaz dejó oficialmente la dirección poco después de la Batalla de Carabobo, el 24 de junio de 1821, aunque siguió contribuyendo un tiempo más. Sin embargo, Juan Gutiérrez Díaz fue siempre su impresor, indistintamente bajo órdenes realistas o patriotas (Pérez Vila, 1985, IX, xlvi).

El Correo del Orinoco, por su parte, fue el órgano republicano oficial que Bolívar se vio obligado a fundar desde Angostura, en plena selva amazónica, para contrarrestar la violenta guerra verbal del médico pardo. Circuló también con sorprendente regularidad durante esos cuatro años, casi siempre los sábados, desde el 27 de junio de 1818 hasta el 23 de marzo de 1822 . En él se publicaron los documentos fundacionales republicanos, incluidos el "Tratado de Regularización de la Guerra" (1820) y el famoso "Discurso de Angostura". Respecto de este último, desde la Gaceta..., en siete diferentes entregas tituladas "Manifiesto de las Provincias de Venezuela a todas las provincias civilizadas de Europa", Díaz intentó contrarrestar el inminente triunfo patriota analizando minuciosamente el discurso de Bolívar.

Ambos periódicos no solo informaban a conveniencia lo que iba ocurriendo en el campo de batalla e imprimían textos variados -especialmente cartas y correspondencia en general- que interceptaban al enemigo, también publicaban los documentos oficiales que componían el aparato legal de cada bando. "El Público ilustrado" -así califica a sus lectores el primer número del Correo...- se enteraba de lo que ocurría en el resto del mundo mediante la transcripción de lo que aparecía en otras gacetas, se "aclaraban" los engaños enemigos, o se inventaban proclamas y acontecimientos para despistar al bando contrario. La figura del editor era sumamente importante, pues este se ocupaba de refutar explícitamente la información comprometedora y de realizar los análisis correspondientes (en el caso de Díaz, en particular, este apelaba reiteradamente a la letra cursiva al intervenir los textos, de esta manera le indicaba fácilmente al lector la proposición que era "corregida" o comentada). En el período que nos interesa, el editor de la Gaceta... fue casi siempre, como acabo de señalar, José Domingo Díaz; en el caso del Correo... se cree que los primeros doce números fueron dirigidos por Francisco Antonio Zea y luego le siguieron en distintos momentos el ya mencionado Juan Germán Roscio, Vicente Salias (enemigo confeso de Díaz), Manuel Palacio

\footnotetext{
7 Bajo la dirección de Díaz, a partir del $1^{\circ}$ de febrero de 1815, la Gazeta... pasó a llamarse Gaceta..., con "c".

8 En cada uno de los volúmenes de la edición facsimilar que he trabajado, editados por Manuel Pérez Vila, aparecen muy claramente detallados los números que no se han encontrado y la especificidad de cada edición ordinaria o extraordinaria.

9 Para un estudio detallado de cada una de sus etapas, cfr. Alcibíades.

10 Con breves interrupciones (cfr. Alcibíades, 31).
} 
Fajardo, José Rafael Revenga y José Luis Ramos. Es muy difícil precisar esta información porque, en el caso patriota, se asumía esta función como responsabilidad colectiva, por lo que la mayoría de las intervenciones con contenido editorial se firmaban con seudónimos como El Apureño, El Mosca, El Fisgón, El Americano, El Colombiano, El enemigo de los tiranos...

Al revisar ambos impresos, destaca un contrapunteo recurrente, donde se apela a la intertextualidad como recurso particular para sostener sus respectivos relatos ${ }^{11}$. El número 59 del periódico patriota, publicado el 22 de abril de 1820, nos aclara, por ejemplo, que se ha visto obligado a extender su cobertura por las presiones escriturales realistas:

No ha sido costumbre anunciar en el Correo del Orinoco las operaciones que intentan nuestros ejércitos, contentándonos con publicar el resultado. Pareciera esto lo más prudente y conforme a las reglas de la guerra. Mas la Gaceta de Caracas abusa demasiado de nuestro silencio [...] Para detener la circulación de semejantes imposturas, hablaremos una y otra vez de los movimientos preparatorios de nuestro ejército, ó de sus marchas y posiciones...

No puede pensarse un periódico sin el otro pues, en esa intensidad que arropa a la meseta independentista, cada editor debía estar pendiente de lo que publicaba su rival, organizando su mensaje en función de ello e intentando anticipar o, al menos, minimizar los avances del enemigo.

José Domingo Díaz basaba sus acusaciones ideológicamente en el caos que había traído la guerra por culpa de las ideas extranjeras que los jóvenes mantuanos de su generación se empeñaban en instaurar; insistía en las bondades del régimen monárquico, así como en la falta de madurez del pueblo para asumir cualquier otra forma de gobierno que lo alejara de la bondadosa protección de la Monarquía, bajo cuya sombra debían permanecer sin ninguna duda las colonias americanas. Bolívar, por su parte, siempre se mostró desconfiado de la capacidad de quienes lo acompañaban para implementar debidamente, luego de la guerra, las exigentes virtudes republicanas; de allí el recrudecimiento de sus posturas políticas a medida que iba avanzando la contienda bélica (evolución que no se le escapaba a Díaz en su seguimiento de las ideas y la actuación del máximo jefe patriota, a quien acusaba con frecuencia de dictador).

Según Elías Pino Iturrieta, el discurso realista -muy en particular el de Díaz- fue muy "pobre en bagaje doctrinario" (1997 82), por lo cual recurría reiteradamente, por un lado, a la episteme clásica de confrontación singularizada entre la figura del rey Fernando VII y Simón Bolívar y, por el otro, a tres principios doctrinarios: el derecho divino de los reyes, la soberanía popular y la igualdad (1997 85). Las armas ideológicas esgrimidas para el

11 He encontrado cuatro textos que analizan y contraponen ambos periódicos: Rodríguez (123-146), Pino Iturrieta (1977), Navarro García y Barrera Padilla (2006) y Gómez (2013). 
ataque, según Pino Iturrieta, se emparentaban con las que utilizaron los ultramontanos para desacreditar a los pensadores ilustrados. Como ellos, Díaz "acude al trillado argumento relativo a la vida afectiva, que ve en el descarrío revolucionario un producto de la irrupción de las pasiones [...] los revolucionarios [Bolívar y sus allegados más cercanos] quedaban reducidos a la condición de seres incapaces de moderar su vida anímica; a representar el rol de [...] los antiguos herejes" (84-85).

Los editores del Correo... apelaban, por su parte, a la leyenda negra antiespañola, citando a la cabeza a fray Bartolomé de las Casas y transcribiendo por entregas numerosos tratados, además de extractos de gacetas tanto francesas como inglesas, norteamericanas y del resto del Caribe e Hispanoamérica. Fernando VII y José Domingo Díaz constituían el núcleo personalizado de la crítica a la mala gestión peninsular; los dos aparecen recurrentemente cuestionados, aunque Díaz llevaba el protagonismo en los insultos y caricaturizaciones:

El Redactor de la Gaceta de Caracas es veterano, no sólo en mentir, sino en falsificar. Si antes ha vivido de su lengua, ahora vive de su pluma. Nadie extraña que un personaje tan ridículo y despreciable se haya propuesto hacerse un nombre con su interminable charla de sandeces y chismes. Pero un gobierno, si es que hay Gobierno bajo un sistema absurdo, bárbaro, y tiránico; un Gobierno que pretende parecerlo, no debe permitir por su propio decoro que su Gaceta oficial sea una compilación indigesta de imposturas groseras, de citas falsas, de discursos necios; y el libelo en fin más despreciado de cuantos libelos despreciables han deshonrado las letras (Correo 6, 1 de agosto de 1818).

Pese a la opinión generalizada, defendida por Pino Iturrieta, una lectura detallada de la Gaceta en los años que nos ocupan muestra que no es tan certero que en los textos de Díaz tuvieran prioridad sus insultos y no apelara a ningún tipo de argumentación lógica "moderna"; por el contrario, como bien afirman Navarro García y Barrera Parilla, lo que ocurre es que abundan "las opiniones 'inconvenientes' a la causa patriótica, las sospechas respecto a la conducta del enemigo republicano" (117-118). En el caso de sus Memorias sobre la Rebelión de Caracas el tono, por la misma naturaleza genérica del texto, sí ahonda más en ese enfrentamiento personalizado. Las estrategias de representación resultan muy similares en ambos libelos, así como la tergiversación de las ideas del bando contrario. La historiografía venezolana suele destacar los horrores realistas, como si los patriotas no hubieran pecado del mismo mal. En todo caso, el tono desde el Correo, tampoco era, como acaba de mostrarse en la larga cita anterior, el más comedido.

El mismo Simón Bolívar -bajo seudónimo- parece haber publicado en el Correo... al menos un par de textos bastante agresivos dirigidos directamente a Díaz. El 27 de febrero de 1819, por ejemplo, en el número 20, apareció una carta firmada por un tal J. Trimiño, encabezada con el título "Carta al redactor de la Gaceta de Caracas", donde se describe el mal estado de las tropas realistas, a pesar de los alardes del médico editor, que se contraponen a los 
recientes éxitos republicanos (Pérez Vila). Para reforzar su argumentación, "Trimiño" recurre a cartas interceptadas de oficiales realistas, además de a insultos y descalificaciones, para terminar de la siguiente manera:

No escriba V. más, Caballero Díaz. Ya que no sabe escribir bien podrá guardar silencio que es lo que V. haría admirablemente, cuando ignora cuanto se requiere saber para ser buen escritor. ¿Sabe V. pensar? No. ¿Sabe V. lo que es verdad? No. ¿Sabe V. decirla? No. ¿Pues qué sabe V.? Mentir, adular al que teme, calumniar al que aborrece, siempre contradecirse y fastidiar a todo el mundo [...] V. no es nada ni será nunca más que nada.

Luego del éxito republicano en la batalla de Carabobo (el 24 de junio de 1821), donde se obtuvo oficialmente la independencia venezolana del yugo español, el Correo... publicó, al día siguiente, en un número extraordinario, el informe correspondiente elaborado por Simón Bolívar. Como nota nada despreciable, dicho informe apareció simultáneamente en tres idiomas: castellano, inglés y francés. En el texto, Bolívar destaca particularmente la conducta de José Antonio Páez en la que califica como "la más gloriosa victoria de Colombia". En reconocimiento a ello, y a nombre del Congreso, relata que Páez fue condecorado por él, en el mismo campo de batalla, con el rango de General en Jefe del Ejército. Bastin, Navarro e Iturriza afirman que el Correo... "publicaba noticias en inglés y francés debido a que circulaba en las islas del Caribe y se difundía también, en forma muy restringida, en los Estados Unidos y Europa" $(2010,196)$. En la edición facsimilar que he trabajado, Gerardo Rivas Moreno sostiene que el periódico "entraba a España por Gibraltar, y de allí algunos ejemplares llegaban a los puertos de Inglaterra" (vii).

La Gaceta..., por su lado, estuvo menos preocupada por la transcripción de noticias internacionales a partir de la salida del Correo... y, sobre todo, cuando se fue acercando la inminente derrota final. Lo que sí le interesaba, y mucho, era mantener el contacto con la población civil. Al respecto, Tomás Straka ha destacado que "el gacetero", como también se le conocía a Díaz en su época, "no era una voz que clamaba en solitario. Siempre gozó de una amplísima audiencia, que llegó a ser mayoritaria durante casi todo el tiempo que estuvo a cargo de la Gaceta" (2009 8). Para lograr su objetivo, Díaz insiste en mostrar una visión idealizada de la monarquía española -a la que califica como "la edad de oro"12-, gracias a ella, por ejemplo, las relaciones entre los esclavos y los propietarios latifundistas eran armoniosas (su manera de justificar el apoyo de este grupo a la monarquía hasta bien entrada la contienda). Este contacto con la población civil era igualmente importante para el Correo... Para ambos periódicos, pese a estar sumergidos en una guerra, el seguimiento de la población civil les permitía alejarse, así fuera temporalmente, de lo estrictamente militar; por ello los editores se ocupaban de publicar textos reflexivos (quizá efectivamente más extensos

12 Cfr. Barrera y Navarro García. 
y reiterativos en el caso de Díaz, precisamente porque en el bando realista no interesaba la construcción de un nuevo Estado).

En asiduas oportunidades, Díaz se dirige en sus intervenciones directamente a Bolívar. Probablemente en diciembre de 1818, con su acostumbrada arrogancia, le expresa cómo el triunfo de la Monarquía podría obtenerse, al menos en parte, desde las páginas de su periódico:

iOjalá Simón, que llegue el momento en que tu audacia te precipite a decirlo, porque en ese venturoso día mi triunfo sobre ti será definitivo, y tendré el placer de ver completada tu ruina con solo anunciarlo! Si ahora me es necesario espiarte sin cesar, observar tus acciones, y meditar en tus palabras para ponerme en estado de que acabe de conocerte; entonces con un solo golpe yo me vería libre de semejantes tareas [...] Nosotros no esperamos, ni pedimos á los gobernadores de las Antillas hombres, armas, ni municiones. No nos importa para nuestra causa la opinión que en ellas se forme de nuestra situación, ni de nosotros; porque esta opinión solo será la de unos particulares cuya influencia nos es insignificante [...] Hacemos en fin la guerra con la opinión y los grandes recursos de una vasta monarquía [...] Tú que presides un gobierno que nadie reconoce $[. .$. tú sí necesitas de la opinión de las Antillas.

Para terminar, quisiera reiterar la importancia de profundizar en las lecturas que insisten no solo en el carácter tradicional de la Gaceta... en los años definidores de la contienda bélica, sino en el empleo deficiente de todo tipo de recursos, incluso escriturales, que obligan a descalificar, por inconsecuente y superficial, el estudio del libelo realista. Ambos periódicos respondieron a su tiempo y reproducen estrategias similares, a pesar de representar posturas ideológicas irreconciliables. Por otro lado, espero haber mostrado cómo no puede pensarse el uno sin el otro, pues desde su nacimiento el Correo... vio la luz precisamente para contrarrestar la influencia de José Domingo Díaz y sus escritos en la Gaceta... Se le ha otorgado una supremacía en todos los ámbitos al Correo... que creo necesario descentrar. Es ineludible un estudio de la meseta independentista en todos sus aspectos, incorporando lo más posible a los dos bandos, e incluyendo el conflicto racial al interior del propio grupo letrado. Esto permitirá finalmente esa desmitificación tan necesaria, en mi criterio, de los inicios republicanos en el imaginario venezolano.

\section{Obras citadas}

Alcibíades, Mirla. "Historia y trayectoria de la Gaceta de Caracas". Cuadernos de Ilustración y Romanticismo 16 (2010): 1-35.

Archila, Ricardo. "El médico José Domingo Díaz contemplado por otro médico del siglo XX". Boletín de la Academia Nacional de la Historia". LIII. 210 (abril-junio 1970): 197-225.

Azpurua, Francisco de. "Breves observaciones a los Recuerdos sobre la Rebelión de Caracas". Anuario. Instituto de Antropología e Historia 4-6.2 (1969): 1097-1113. 
Barrera, Beatriz y Jesús Raúl Navarro García (2006). "La Edad de Oro como proyecto de patria y el modelo caballeresco en los panfletos del polemista José Domingo Díaz (1826-1828)". Insurgencia y republicanismo. Jesús Raúl Navarro García ed. Sevilla: Consejo Superior de Investigaciones Científicas, pp. 133-152.

Bastin, Georges L., Aura Navarro y María Gabriela Iturriza (2010). "La prensa independentista venezolana (1808-1822) desde la traducción". De Independencias y Revoluciones. Avatares de la modernidad en América Latina. Gastón Lillo y Leandro Urbina eds. Santiago de Chile: Editorial LOM, pp. 193-213.

Borges, Jorge Luis (1975). "Tema del traidor y del héroe". Barcelona: Círculo de Lectores, pp. 328-330.

(2016). Tema del traidor y del héroe: edición crítico-genética. Buenos Aires: Biblioteca Nacional.

Brice, Ángel Francisco (1961). "Estudio preliminar". Recuerdos sobre la Rebelión de Caracas". José Domingo Díaz. Caracas: Academia Nacional de la Historia, pp. 15-40.

Carrera Damas, Germán (1973). El culto a Bolívar. Esbozo para un estudio de la Historia de las Ideas en Venezuela. Caracas: Universidad Central de Venezuela.

Castellanos, Rafael Ramón. "Apuntaciones sobre los 'Recuerdos de la Rebelión de Caracas'". Revista Bolívar I.2 (24 de julio de 1959): 1-8.

Castro Leiva, Luis (1991). De la patria boba a la teología bolivariana. Ensayos de historia intelectual. Caracas: Editorial Monte Ávila.

Conway, Christopher. "Letras combatientes: género epistolar y modernidad en la Gaceta de Caracas, 1808-1822". Revista Iberoamericana LXXII. 214 (enero-marzo 2006): 77-91.

Correo del Orinoco. Angostura (Venezuela) 1818-1821. Edición Facsimilar (1998) Bogotá-Bucaramanga: Fundación Fica.

Díaz, José Domingo (1829). Recuerdos sobre la Rebelión de Caracas. Madrid: Imprenta de D. León Amarila.

Escalona, Roger y Gabriel Escalona. "José Domingo Díaz, el que no fue profeta en su tierra". Revista de la Sociedad Venezolana de la Historia de la Medicina 58.1-2 (2009): 105-109.

Febres Cordero, Julio (1974). Historia del periodismo y la imprenta en Venezuela 1810-1830. Caracas: Banco Central de Venezuela. (1964). "Los redactores del Correo del Orinoco". Establecimiento de la imprenta en Angostura. Caracas: Universidad Central de Venezuela, pp. 179-191.

García Peña, Eduardo. "Reflexiones políticas de dos universitarios: Miguel José Sanz y José Domingo Díaz en el Semanario de Caracas (18101811)". Temas de Comunicación 17 (2008): 35-54.

Gómez, Alejandro. "Las revoluciones blanqueadoras: élites mulatas haitianas y 'pardos beneméritos' venezolanos, y su aspiración a la igualdad, 1789-1812". Nuevo Mundo Mundos Nuevos 868 (19 de marzo de 2005). "La Revolución de Caracas desde abajo". Nuevo Mundo Mundos Nuevos 868 (17 de mayo de 2008).

(2006). "Del affaire de los mulatos, al asunto de los pardos". Las revoluciones en el mundo atlántico. María Teresa Calderón y Clément Thibaud eds. Bogotá: Centro de Estudios de Historia-Taurus. 
Gómez, Argenis (2013). Historia de un antihéroe: obra científica y labor periodística del doctor José Domingo Díaz (1772-1842?). Caracas: Universidad Central de Venezuela.

Gómez Pérez, Argenis J. "El Doctor Díaz y el Arzobispo Coll y Prat". Instituto de Estudios Hispanoamericanos 10 (1998): 63-72.

Grases, Pedro (1982). La imprenta en Venezuela. Estudios y monografías. Barcelona: Seix Barral, vols. I-II.

Heredia, Edmundo A. (1997). Los vencidos. Un estudio sobre los realistas en la guerra de independencia hispanoamericana. Córdoba: Universidad Nacional de Córdoba.

Langue, Frédérique. "La pardocratie ou l'itinéraire d'une «classe dangereuse» dans le Venezuela des XVIIIe et XIXe siècles". Caravelle 67 (1977): 57-72.

Lasso, Marixa (2007). Myths of Harmony. Race and Republicanism during the Age of Revolution, Colombia 1795-1831. Pittsburgh: University of Pittsburgh Press.

Lombardi, John V. "Los esclavos en la legislación republicana de Venezuela". Boletín Histórico 7.14 (1966): 43-67.

Lombardi Boscán, Ángel Rafael (2006). Banderas del Rey (La visión realista de la Independencia). Maracaibo: Ediciones del Rectorado. Universidad del Zulia.

"Fin de la presencia realista en Venezuela: la Monarquía como patria (1810-1823)". Cuadernos de Historia Moderna XI (2012): 185-197.

Lovera de Sola, Roberto. "José Domingo Díaz, el jefe intelectual del Partido Realista de Caracas". arteenlared.com (20 de febrero de 2015).

Lynch, John (1973). The Spanish American Revolution 1808-1826. New York-London: W. W. Northon \& Company.

Machado, José Eustaquio. "La 'Gazeta de Caracas'". Orígenes de la imprenta en Venezuela y primicias editoriales de Caracas. Pedro Grases ed. Caracas: Edición de El Nacional, pp. 313-315.

Mangano-Molero, Francisco (1958). "Visiones de un vencido. Joseph Domingo Díaz testigo ocular de la Revolución de Venezuela (1810-1824)". Memorias 7.12 (julio, 2010): 48-69.

Navarro García, Jesús Raúl (1999). Puerto Rico a la sombra de la independencia continental (Fronteras ideológicas y políticas en el Caribe, 1815-1840). Sevilla-San Juan: Centro de Estudios Avanzados de Puerto Rico y el Caribe/Escuela de Estudios Hispano-Americanos.

y Beatriz Barrera Padilla (2006). "Con la pólvora en el tintero: propaganda y contrainsurgencia en la Venezuela republicana. El ejemplo de José Domingo Díaz". Insurgencia y republicanismo. Jesús Raúl Navarro García ed. Sevilla: Consejo Superior de Investigaciones Científicas, pp. 105-132.

Parra Márquez, Héctor. "A propósito de la esquina del Dr. Díaz. Recuerdos de dos anti-próceres. Rasgos biográficos de tales personajes. Su significación en nuestra historia. Noticias acerca del padre de José Domingo Díaz". Boletín de la Academia Nacional de la Historia 176 (1961): 538-563.

Pérez Vila, Manuel (1968). Campañas periodísticas del Libertador. Maracaibo: Universidad del Zulia.

ed. (1984). Gaceta de Caracas. Caracas: Academia Nacional de la Historia, vol. VII. 
. (1985). Gaceta de Caracas. Caracas: Academia Nacional de la Historia, vols. VIII-IX.

"Nota preliminar". Gaceta de Caracas. Caracas: Academia Nacional de la Historia, vol. IX, pp. xliv-xlix.

Pino Iturrieta, Elías (1998). Ideas y mentalidades de Venezuela. Caracas: Biblioteca de la Academia Nacional de la Historia.

(1991). La mentalidad venezolana de la emancipación. Caracas: Ediciones El Dorado.

(1997) Nueva lectura de la Carta de Jamaica. Caracas: Monte Ávila Editores Latinoamericana.

"Tradicionalismo y modernidad en la justificación oficial de la independencia venezolana". Boletín Histórico 25.27 (1971): 21-32.

Quintero, Inés (2011). "Estudio preliminar". Recuerdos sobre la Rebelión de Caracas. José Domingo Díaz. Caracas: Academia Nacional de la Historia, pp. 11-50.

"Sobre la suerte y pretensiones de los pardos". Bastillas, cetros y blasones: la independencia en Iberoamérica. Ivana Frasquet Miguel coor. Madrid: Fundación Mapfre, 2006, pp. 327-345.

Ramírez Martín, Susana María. "José Domingo Díaz, un médico venezolano al servicio de la causa realista". XIV Encuentro de Latinoamericanistas Españoles. Sep. 2010, Universidad de Santiago de Compostela, Centro Interdisciplinario de Estudios Americanistas. Gumersindo Busto Rey Tristán, Eduardo y Patricia Calvo González eds., pp. 149-166.

Ríos, Alicia. "El Correo del Orinoco: prensa y nación en la Venezuela independentista". Estudios 9 (1997): 127-138.

"La guerra y la prensa: aparatos de captura del Estado republicano (Venezuela, 1818-1822)". Estudios 11 (1998): 107-117.

(2013). Nacionalismos banales: el culto a Bolívar. Literatura, cine, arte y política en América Latina. Pittsburgh: IILI.

Rodríguez, Manuel Alfredo (1969). El Correo del Orinoco, periódico de la emancipación americana. Caracas: Academia Nacional de la Historia. (1992). Los pardos libres en la colonia y la independencia. Discurso de incorporación como individuo de número de la Academia Nacional de la Historia. Caracas: Academia Nacional de la Historia.

Rodríguez Cárdenas, Manuel. "José Domingo Díaz". Crónica de Caracas X.58 (1963): 540-543.

Rosas Marcano, Jesús. "La prensa realista entre 1820 y 1821 ". Boletín Histórico 38 (1975): 171-186.

Sosa Cárdenas (2010). Los pardos. Caracas en las postrimerías de la Colonia. Caracas: Universidad Católica Andrés Bello.

Straka, Tomás (2007). La voz de los vencidos. Ideas del partido realista de Caracas, 1810-1821. Caracas: bid \& co. editor.

ed. (2009). Contra Bolívar. José Domingo Díaz. Contra Díaz. Simón Bolívar. Caracas: Editorial Libros Marcados.

"El periodismo que nació con la revolución. Un vistazo a los periódicos, a las imprentas y a sus leyes durante la Primera República de Venezuela, 1810-1812". Temas de comunicación 17 (2008): 13-34.

Tovar Núñez, Marianela (2012). "Prólogo. En busca del paraíso perdido: la vivencia de José Domingo Díaz de la guerra de independencia en Venezuela". Recuerdos sobre la Rebelión de Caracas. José Domingo Díaz. Caracas: Biblioteca Ayacucho, pp. IX-LVII. 